\title{
Child English pre-sentential negation as metalinguistic exclamatory sentence negation*
}

\author{
KENNETH F. DROZD \\ Max-Planck-Institut fuer Psycholinguistik
}

(Received: 22 February 1994. Revised: 25 fanuary 1995)

\section{A BSTRACT}

This paper presents a study of the spontaneous pre-sentential negations of ten English-speaking children between the ages of $1 ; 6$ and $3 ; 4$ which supports the hypothesis that child English nonanaphoric pre-sentential negation is a form of metalinguistic exclamatory sentence negation. A detailed discourse analysis reveals that children's pre-sentential negatives like No Nathaniel a king (i) are characteristically echoic, and (ii) typically express objection and rectification, two characteristic functions of exclamatory negation in adult discourse, e.g. Don't say 'Nathaniel's a king'! A comparison of children's pre-sentential negations with their internal predicate negations using not and don't reveals that the two negative constructions are formally and functionally distinct. I argue that children's nonanaphoric pre-sentential negatives constitute an independent, well-formed class of discourse negation. They are not 'primitive' constructions derived from the miscategorization of emphatic no in adult speech or children's 'inventions'. Nor are they an early derivational variant of internal sentence negation. Rather, these negatives reflect young children's competence in using grammatical negative constructions appropriately in discourse.

\section{INTRODUCTION}

Developmental studies of negation commonly observe that young English speakers produce nonanaphoric 'preclausal' negation (Bellugi, 1967), which I shall refer to as PRE-SENTENTIAL NEGATION. The clear cases of pre-sentential negation consist of an utterance-initial, nonanaphoric, negative morpheme no, or much less often, never or not, followed by a SENTENCE consisting of an

[*] I would like to thank Harald Baayen, Lois Bloom, Melissa Bowerman, Jill De Villiers, Larry Horn, Susan Powers, Wolfgang Klein, Tom Roeper, Catherine Snow and an anonymous reviewer for helpful comments and discussions regarding the ideas presented in this paper. Any mistakes and (mis)interpretations of data are my own. The research presented here is an extension of the author's dissertation research. Address for correspondence: Kenneth F. Drozd, Max-Planck-Institut fuer Psycholinguistik, Postbus 310, NL-6500 AH, Nijmegen, The Netherlands. Email: DROZD@mpi.nl. 
overt subject and predicate, e.g. verb phrase, predicate nominal, or predicate adjective (No is treated as the typical pre-sentential negation marker in this paper). A NONANAPHORIC use of a pre-sentential negation marker is one which applies negation to the sentence it occurs with to its right, e.g. No the sun shining. This is to be distinguished from an ANAPHORIC use of a presentential negation marker which applies negation to a previous utterance or situation (Bloom, 1970), e.g. A: Do you want to eat inside?, B: No, I want to eat outside. Henceforth, the term 'pre-sentential' refers only to the nonanaphoric uses. Left out of the discussion are the so called 'subjectless' presentential negations consisting of a negative marker followed by a predicate, because of their controversial status as genuine examples of pre-sentential negation (Bloom, 1970/1991; De Villiers \& De Villiers, 1985). Instead, the use of negative complements with subjects is treated as a criterial feature of pre-sentential negation (Bloom, I 970; De Villiers \& De Villiers, 1985). (See Drozd (1993) for further discussion.)

Since Klima \& Bellugi (1966) presented their grammar of child English negation, pre-sentential negation has typically been viewed as non-adult-like. It is commonly described as 'primitive' (De Villiers \& De Villiers, I 979:64), 'the child's own invention' (Brown, Cazden \& Bellugi, I969: 305), or generally incompatible with grammatical English (Bellugi, 1967; McNeill, 1970; Bowerman, 1973; Pierce, 1992; Deprez \& Pierce, 1993). In formal syntactic analyses, pre-sentential negation is commonly referred to as evidence for an early pre-adult stage (Period I (Bellugi, 1967)) in the progressive development of INTERNAL SENTENCE NEGATION (or simply INTERNAL NEGATION), which can be defined as sentence negation in which the negative marker, not, $n^{\prime} t$, don't etc., occurs between subject and predicate. Elliptical sentence negations like $N o, I$ don't have rarely been discussed in previous literature and are not considered here either.

One crucial but often implicit assumption in these and other studies is that nonanaphoric pre-sentential no is a suppletive alternant for the internal sentence negation marker not. When children have acquired the grammatical mechanisms responsible for correctly placing no/not in preverbal position after a subject, they are assumed to have entered a subsequent, more mature, developmental stage corresponding to Bellugi's Period 2. At this stage, children begin to use internal sentence negation productively, e.g. I not copy cat, I no taste them, and the use of pre-sentential negation seems to disappear. Analyses differ with respect to the categorization of no/not and the kinds of linguistic mechanisms responsible for the realization of internal sentence negation. For a critical summary, see Drozd (1993).

An influential alternative view most persuasively argued by Bloom and colleagues (Bloom, I 970; Bloom, Miller \& Hood, I975; Bloom \& Lahey, 1978; Bloom, 1991) claims that 'a stage of sentence external negation in early acquisition is a myth (Bloom, I991: 144$)^{\prime}$. Bloom (1970) discovered that the 
vast majority of putative examples of pre-sentential negation in the speech of her subject, Kathryn, were examples of anaphoric negation. Other examples, such as Nicholas's rejection No Mummy do it (De Villiers \& De Villiers, 1979) are interpreted as the negation of an unexpressed matrix verb want, e.g. [I] no [want] Mommy do it (deleted items in square brackets), rather than the negation of the sentence with which the negative marker co-occurs in the utterance.

Considerable attention has been given to the functional categorization of children's negative utterances in English (Bloom, r970/199r; Greenfield \& Smith, I 976 ; Volterra \& Antinucci, r 979; Keller-Cohen, Chalmer \& Remler, I 979; Choi, I988). However, functional assignments to pre-sentential negatives are seldom made with confidence. One reason for this is that presentential negations occur at an extremely low frequency and are often ambiguous, even when the context of utterance is consulted to aid in interpretation. Another reason is that children use negative utterances in general to express a wide range of pragmatic meanings which are often not immediately captured by standard accepted categorial definitions (Bowerman, I973; Volterra \& Antinucci, 1979).

Pre-sentential negatives are classified as either (polite or imperative) rejections or denials (Bloom, I970/1991; Bloom \& Lahey, 1978; De Villiers \& De Villiers, 1 979; 1985) using definitions like the following (adapted from Bloom, I970; Bloom \& Lahey, I978; De Villiers \& De Villiers, 1979) and examples from various published studies.

REJECTION: Object, action, or event either existing or imminent in context is opposed by the child (Bloom, r 970 ).

POLITE Involves things the child does not want to do or to REJECTION: have.

Paraphrase: I don't want $X$.

Nicholas $(1 ; 1 \mathrm{I}-2 ; 5)$ No

(Bloom, I 991 , example

Mummy do it. (= I don't want taken from De Villiers

Mommy to do it)

\& De Villiers, 1979)

IMPERATIVE Involves events the child does not want another person

REJECTION: $\quad$ to do. (Bloom \& Lahey, I 978).

Paraphrase: don't $X /$ mustn't $X$

Eve $(1 ; 9)$ No Mommy giving

(De Villiers \& De

baby Sarah milk. (= Mommy Villiers, r 979)

mustn't give baby Sarah

milk)

DENIAL: Negation of the truth of a statement made by someone else (Bloom \& Lahey, 1978).

Paraphrase: It is not true that $X$ 
Adam (2;4) No a boy bed (= The boy's not in bed) Adam $(2 ; 4)$ : No the sun shining ( $=$ The sun's not shining).

Adam $(2 ; 3):$ No I see truck (= I didn't see the truck).

Nina $(2 ; 0)$ : No Mommy doing (= Mommy's not doing).

Nina $(2 ; 0)$ : No lamb have it (= The lamb doesn't have it)
De Villiers \& De

Villiers, 1979)

(De Villiers \& De

Villiers, 1979)

(Brown \& Bellugi, 1964)

(Deprez \& Pierce, 1993)

(Deprez \& Pierce, 1993)

There have been no attested examples of pre-sentential negation used to express other functions like nonexistence. I return to this point below.

\section{Metalinguistic exclamatory sentence negation}

Children's nonanaphoric pre-sentential negation strongly resembles metalinguistic exclamatory sentence negation in colloquial adult English. This observation underlies the hypothesis in this paper that children's presentential negatives are examples of metalinguistic exclamatory sentence negation - a grammatical, acceptable use of sentence negation in English discourse.

The perspective advanced here crucially depends on the distinction between metalinguistic and descriptive negation described in detail by Horn (1989). Horn proposes that ordinary internal sentence negation represents one of two logical operations which give rise to two interpretations, (i) DESCRIPTIVE NEGATION, which expresses truth-functional denial, e.g. It is not true that $S$, and (ii) METALINGUISTIC NEGATION, which is defined as 'a device for objecting to a previous utterance on any grounds whatever, including the conventional or conversational implicata it potentially induces, its morphology, its style or register, or its phonetic realization' (Horn, 1989: 363). Horn glosses this meaning as $I$ object to $U$, where $U$ is an utterance or utterance type, though other more specific predicates like Don't say $U$ (to me) or Don't use $U$ that way can be considered as equivalent glosses.

Metalinguistic interpretations arise via two pragmatic patterns of inference, the Q PRINCIPLE, based on Grice's (1975) first Quantity Maxim of Conversation, and the R PRINCIPLE, drawn from Grice's Relation Maxim. The $Q$ pattern is exemplified in ( $\mathrm{I}$ ).

(I) Speaker A: It's stewed bunny.

Speaker B: It's not stewed bunny, it's civet de lapin.

Here, Speaker B is aware that Speaker A has used an inappropriate or weak 
term, stewed bunny, given some pragmatic scale of appropriateness. Given no evidence that Speaker $A$ is not co-operating in the discourse, Speaker B assumes under the $\mathrm{Q}$ Principle that Speaker $\mathrm{A}$ is being as appropriate or informative as she can. Using metalinguistic negation, Speaker $B$ cancels the inappropriate term and replaces or contrasts it with a more appropriate or stronger term, civet de lapin, in a rectification. Here, the target of Speaker B's negative is not the truth value of Speaker A's utterance, as in descriptive negation, but the social inappropriateness of the particular term in the previous utterance.

The $\mathrm{R}$ pattern of inference is characteristic of euphemistic language in which a speaker uses a weak polite form to avoid using a stronger, more specific form which would directly convey a negative meaning. For example, yes/no questions like Can you close the window? are conventionally used as indirect speech acts to communicate more specific requests like Close the window! Also, lexical items like married are tied by convention to narrower meanings, e.g. married to each other, which can be specifically negated without disturbing the truth value of the original utterance, as in (2).

(2) Speaker A: Chantal and Reynaldo are married.

Speaker B: Chantal and Reynaldo aren't married. Chantal is married to Geert and Reynaldo is married to Angelique.

Several pre-sentential negation constructions exist in English to express metalinguistic negation. One kind is CONTRASTIVE SENTENCE NEGATION in which a sentence is preceded by not, e.g. A: It's stewed bunny. B: Not 'it's stewed bunny'. It's civet de lapin. Putative examples of contrastive sentence negation in child English are discussed below.

Horn ( 1 989: 402) uses exclamatory sentence negatives, e.g. Like hell I still love you!, as examples of metalinguistic negation, but does not discuss them in detail. However, the connection is straightforward. METALinguistic EXCLAMATORY SENTENCE NEGATION (or simply EXCLAMATORY NEGATION) can be defined as the use of one of a small, closed set of idiomatic phrases, e.g. like fudge, phooey, my ass, my foot, my eye, nonsense, bullshit, like hell, the hell, the fuck, the heck, the devil, bullcookies, poppycock, yeah right, horsehockey, no way, bollocks, bull crud, crap, fuckall, like fish, don't say, followed by a sentence (defined above) to express objection and/or rectification.

Exclamatory negation and metalinguistic internal sentence negation share a number of properties: $(i)$ they both express Q-based or R-based metalinguistic negation rather than descriptive negation; (ii) they are both echoic, and (iii) they neither inhibit the use of positive polarity items (PPIs) nor trigger the use of negative polarity items (NPIs) (Horn, 1 989). For example, speaker B's utterances in (I) and (2) can be replaced by the following exclamatory sentence negations, suggesting that exclamatory negation is interpreted in terms of the $\mathrm{R}$ and $\mathrm{Q}$ Principles. 
(3) Don't say it's stewed bunny, it's civet de lapin.

(4) No way are Chantal and Reynaldo married. Chantal is married to Geert and Reynaldo is married to Angelique.

Second, exclamatory negation is generally echoic, and more specifically, echoic up to deixis. Deictic proforms like $I$, here, and this or other constituents like the man or worked quickly in the utterance target may be replaced with proforms, e.g. you, there, that, him, did in the echo to preserve reference, as in A: Harry worked quickly B: No way he did! But more substantial modifications of the target utterance like additional relative clauses, adjuncts, etc. are prohibited (marked *), e.g. A: You proposed to me here. B: *No way I proposed to you here before your divorce!

Further, exclamatory negation generally reflects the syntactic structure and word order of a declarative target, e.g. A: Fohn was happy. B: My foot *was $\mathcal{F o h n / F o h n ~ w a s ~ h a p p y . ~ H e ~ w a s ~ e c s t a t i c ! , ~ t h o u g h ~ n o t ~ o f ~ a n ~ i n t e r r o g a t i v e ~}$ target, e.g. Will you do what I want? B: No way [I will/will $\Pi$ ] do what you want!

Pre-sentential negation as metalinguistic exclamatory sentence negation

Horn (1989: 462) suggests that child English nonanaphoric pre-sentential negation is an early form of metalinguistic negation. In this paper, I argue that this suggestion is correct and should be elevated to a realistic hypothesis about pre-sentential negation in child English. Such a hypothesis, if it is correct, would be an important finding because it would argue for a significant shift in perspective from the currently standard view that children's pre-sentential negatives are primitive, ungrammatical, derivational variants of internal sentence negation. The alternative hypothesis pursued here is that young children use the adult colloquial negation system and, more specifically, the metalinguistic negation system, as a model for their uses of pre-sentential negatives, rather than the internal negation system. Specifically, I argue below that children use phrases like No Nathaniel a king not to express descriptive internal negation, e.g. Nathaniel's not a king ('It is not true that Nathaniel's a king'), but to express metalinguistic exclamatory sentence negation, e.g. Don't say Nathaniel's a king! ('I object to your saying "Nathaniel's a king"!'). Under this view, children's use of pre-sentential negation is considered a reflection of their adult-like competence in using a specific, sophisticated, pre-sentential negative construction which is also used in colloquial English.

Some of the properties of pre-sentential negation summarized above support this hypothesis. First, the fact that pre-sentential negatives are rare in child English can be explained straightforwardly by the fact that exclamatory negation is rare in adult discourse. Second, previous studies report that pre-sentential negation is used to express only two meanings, descriptive 
rejection and denial. Though children learn to express nonexistence using negation early (Bloom, 1970), the use of pre-sentential nonexistence statements like No there's a pony have never been reported. This functional restriction is accounted for if pre-sentential negatives are considered to be expressions of metalinguistic negation, which typically express objection or rectification, but goes unaccounted for in previous syntactic derivational analyses which predict no functional distinction between pre-sentential and internal sentence negation. Moreover, previous descriptions of rejection and denial categories often allude to characteristic properties of metalinguistic negation. Bloom (1970: 173) describes children's denials as negating a referent 'manifest symbolically in a previous utterance' and children's rejections as negations in which a referent 'was rejected or opposed' or simply 'opposed' (De Villiers \& De Villiers, 1 $979: 60$ ) by the child. Negation of a referent manifested in a previous utterance corresponds straightforwardly to the echoic property of metalinguistic negation and the opposition meaning corresponds to what I have described as objection or rectification. ${ }^{1}$

The hypothesis makes two predictions, which are tested in Study I and Study 2.

\section{Prediction $I$}

The first prediction is that children's pre-sentential negations should exhibit characteristic properties of exclamatory negation. First, they should occur with echoic up to deixis complements. This is an unexpectedly strong prediction, since the echoic up to deixis property is reserved for very specific or marked uses of negation. One reasonable alternative would be that children learn to use internal sentence negations first simply because they are

[I] Note that two category names are not simply being replaced with two others here (I thank an anonymous reviewer for bringing the importance of this issue to my attention). Echoic complementation is a criterial property of (metalinguistic) exclamatory sentence negation, as I have shown. But it is not a criterial property of descriptive denial or rejection, as Bloom and De Villiers \& De Villiers define these categories. A rejection like I don't want Mommy to do it may be an echoic response to a previous utterance like Do you want mommy to do it? , or nonechoic, in following an utterance like Where is your mother? Denials can be echoic, e.g. A : Does this work? B: This does not work. or nonechoic, B: I don't think so. Moreover, metalinguistic objection is not equivalent to the opposition meaning commonly associated with the rejection category. Metalinguistic negation characteristically expresses an objection to the manner in which a previous utterance was presented. It is not used to deny that a predicate holds of a subject. Hence, though ( $\mathrm{I}$ ) is acceptable, the following discourse is odd, given that the discourse participants know that bunny stew and civet de lapin are identical objects: 'Speaker A: Do you want bunny stew? Speaker B: ${ }^{*} I$ don't want bunny stew! I want civet de lapin! Lastly, I don't want predicates, in contrast to metalinguistic uses of negation, license negative polarity items and inhibit positive polarity items, e.g. Speaker A: Do you want some mineral water? Speaker B: I don't want any $/$ *some mineral water. 
much more frequent in the input. Moreover, as echoic statements, they should $(i)$ not be used to insert new information into discourse aside from objection to or rectification of the previous utterance; (ii) observe the syntax of a declarative target; and (iii) echo a local previous utterance.

Second, metalinguistic exclamatory negation meanings consistent with the logic of the discourse (when it can be reconstructed from the transcripts) should be recoverable for each pre-sentential negative collected. Expressions like I didn't say that, like hell, no way, don't say, or I object to should be felicitous paraphrases for the negative marker in pre-sentential negatives. If a child uses a negative to exploit Horn's R Principle, then one would expect to find a narrower negative meaning for the previous utterance the child is objecting to, as in the case of yes/no questions. If a child uses a negative to exploit the Q Principle, then one should find her objecting to an inappropriate use of an utterance and, perhaps, replacing the objectionable utterance with a more appropriate one in a tag, though this replacement is not necessary (Wiche, 1991).

This prediction is addressed in Study $\mathbf{I}$.

\section{Prediction 2}

Study $\mathbf{I}$ does not address the assumption that pre-sentential negation is an early derivational variant of internal sentence negation. However, the hypothesis discussed here predicts that this assumption is false. Unlike exclamatory negation, ordinary internal sentence negation is neither typically echoic nor typically used to express metalinguistic negation in adult English (Horn, 1989). We would expect this distinction to be present in child English as well.

Still, this assumption may be true. If Study I showed that children's presentential negatives typically express exclamatory negation, this would not contradict the assumption, since both exclamatory and internal sentence negation express metalinguistic functions in adult English. Children initially may use both negative constructions in the same way, suggesting that a derivational analysis may be appropriate. Further, many of these negatives are consistent with a general rejection interpretation, e.g. I don't want $X$. Thus, it is also not clear that a reductive analysis like Bloom's is inappropriate. However, if it can be shown that children's pre-sentential negation is formally or functionally distinguishable from their internal sentence negations, this can be used as evidence that a derivational or reductive relationship between pre-sentential and internal sentence negation may be misguided.

Prediction 2 is that if children treat pre-sentential and internal sentence negation as distinct negation types, like adult speakers, then their internal sentence negations with not and don't should not characteristically be echoic 
up to deixis. Not/Don't negations were chosen to address Deprez \& Pierce's and De Villiers \& De Villiers' claim that pre-sentential no/not negatives are derivational variants of internal sentence negation. Failure to find internal not/don't negations characteristically echoic up to deixis would be evidence against this claim. Don't utterances were also chosen to address Bloom's (199I) claim that children's pre-sentential no/not negatives are reduced versions of rejections with don't want. A finding that don't want rejections were not characteristically echoic up to deixis would be support for the claim that there is no reductive relationship between pre-sentential no negation and internal don't want rejections.

One would also expect internal not/don't negatives not to be characteristically compatible with metalinguistic exclamatory paraphrases. One piece of evidence supporting this prediction is the functional diversity of children's internal sentence negations (Drozd, 1993), which include nonexistence and descriptive denial statements, e.g. I don't know. This issue is beyond the scope of this paper, however.

\section{STUDY}

\section{METHOD}

The subjects of Study I were 123 children (ages $0 ; 11-3 ; 4$ ) whose spontaneous speech samples are stored on formatted transcript files in the Child Language Data Exchange System or CHILDES (MacWhinney \& Snow, I985). Basic information about these children is summarized in the Appendix. One corpus, the Wisconsin corpus, consisting of data from 48 children, was treated as data from one child, since the children were not distinguished in the transcripts. I chose $3 ; 4$ as the cutoff point because the last nonanaphoric pre-sentential sentence negation using no was uttered at this age (by Iris). The number of speech samples varied widely across children. For some children, e.g. Jeff (Warren-Leubecker \& Bohannon, I 984) only one file was available covering one month of the child's life. Longitudinal data spanning several years were available for other children such as Peter (Bloom, Hood \& Lightbown 1975) and Nina (Suppes, 1973). Of these 123 children, only ro produced at least one analysable pre-sentential negation. The data from these children, as well as the data used in Study 2 , are summarized in Table $\mathbf{I}$.

A search was conducted for all of the pre-sentential negations (anaphoric and nonanaphoric) beginning no, not, and never in the corpora using the KWAL program provided in the CHILDES system. Each use was extracted from the transcript in its discourse window, which consisted of two conversational turns after the child's utterance and three conversational turns before the child's utterance. Apparent copular sentences without a copula verb were included if they had a subject and what appeared to be a predicate, 
TA B LE I. Negative data used in the two studies

\begin{tabular}{|c|c|c|c|c|c|c|c|c|c|}
\hline \multirow{2}{*}{$\begin{array}{l}\text { Study I } \\
\text { Subject }\end{array}$} & \multirow[b]{2}{*}{ Age } & \multirow[b]{2}{*}{ Corpus } & \multicolumn{3}{|c|}{$\begin{array}{l}\text { Anaphoric } \\
\text { pre-sentential } \\
\text { negation }\end{array}$} & \multicolumn{3}{|c|}{$\begin{array}{l}\text { Nonanaphoric } \\
\text { pre-sentential } \\
\text { negation }\end{array}$} & \multirow[b]{2}{*}{ Totals } \\
\hline & & & No & Not & Never & No & Not & Never & \\
\hline Adam & $2 ; 3-3 ; 4$ & Brown & 30 & 0 & 0 & 5 & 0 & 0 & 35 \\
\hline Ben & $1 ; 5-3 ; 2$ & Wells & 0 & 0 & 0 & 0 & I & $\circ$ & I \\
\hline Carl & $3 ; 0$ & Fletcher & o & ० & $\circ$ & 0 & I & ० & I \\
\hline Darren & $1 ; 6-3 ; 3$ & Wells & 9 & o & $\circ$ & I & $\circ$ & $\circ$ & 10 \\
\hline Eve & $1 ; 6-2 ; 3$ & Brown & 33 & $\circ$ & $\circ$ & 3 & 1 & $\circ$ & 37 \\
\hline Iris & $1 ; 6-3 ; 2$ & Wells & I & o & $\circ$ & 2 & o & o & 3 \\
\hline Katie & $3 ; 2$ & Gleason & 7 & o & $\circ$ & $\circ$ & I & o & 8 \\
\hline Lee & $1 ; 5-3 ; 3$ & Wells & 0 & 0 & $\circ$ & 0 & I & $\circ$ & I \\
\hline Nath'l & $2 ; 5-3 ; 4$ & Snow & II & $\circ$ & 0 & 1 & 0 & o & 12 \\
\hline Neil & $1 ; 6-3 ; 3$ & Wells & 0 & $\circ$ & ○ & $\circ$ & 1 & $\circ$ & I \\
\hline Nina & $\mathrm{I} ; \mathrm{II}-3 ; 3$ & Suppes & 131 & $\circ$ & 0 & 6 & I & $\mathbf{I}$ & I 39 \\
\hline Penny & $1 ; 6-3 ; 3$ & Wells & 0 & $\circ$ & $\circ$ & 0 & I & o & 1 \\
\hline Peter & $I ; 9-3 ; 1$ & Bloom* & 203 & o & o & 4 & $\circ$ & - & 207 \\
\hline Totals & & & 425 & $\circ$ & $\circ$ & 22 & 8 & I & $45^{6}$ \\
\hline \multicolumn{3}{|l|}{ Study 2} & \multicolumn{4}{|c|}{$\begin{array}{l}\text { Internal } \\
\text { sentence } \\
\text { negations }\end{array}$} & \multicolumn{3}{|c|}{$\begin{array}{c}\text { Rejections, } \\
\text { denials and } \\
\text { metalinguistic uses }\end{array}$} \\
\hline Subject & Age & Corpus & Don & & Not & Total & Don't & Not & Total \\
\hline Adam & $2 ; 3-3 ; 2$ & Brown & $5^{\circ}$ & & $5^{\circ}$ & 100 & 25 & 42 & 71 \\
\hline Eve & I ;6-2;3 & Brown & 39 & & 32 & 71 & 33 & 22 & 58 \\
\hline Nath'l & $2 ; 5-3 ; 4$ & Snow & 50 & & 35 & 85 & 34 & 31 & 65 \\
\hline Nina & $1 ; 1 I-2 ; 5$ & Suppes & 50 & & 50 & 100 & 34 & 43 & 78 \\
\hline Peter & $1 ; 9-3 ; 1$ & Bloom & 3 & & 50 & 53 & 2 & 32 & 41 \\
\hline Iris & $1 ; 6-3 ; 2$ & Wells & 2 & & 3 & 5 & 2 & 2 & 4 \\
\hline Totals & & & 194 & & 220 & 414 & 130 & 172 & 302 \\
\hline
\end{tabular}

* These data appear in the Bloom 70 corpus in CHILDES. However, the data were collected and compiled by Patsy Lightbown and Lois Hood (Bloom, Lightbown \& Hood, 1975).

e.g. No Nathaniel a king, No the sun shining. I included one formally ambiguous example which was considered to be a pre-sentential negation in previous literature, namely Adam's No a boy bed (e.g. No boy is in the bed (De Villiers \& De Villiers, 1979)). The following negative tokens were excluded from the study: ( 1 ) negatives interrupted internally by pauses, (2) negatives including unintelligible speech, (3) immediate repetitions of identical negatives, (4) rote utterance chunks (e.g. from a song), (5) negatives where the initial negative marker was clearly interpretable as a determiner of a negative subject, e.g. Peter's No one to get him up, Neville's No Achey Ghosties can reach me when I'm upstairs, (6) negatives in which any part of the utterance was marked as questionable by the transcriber, and (7) salutatory 
negations like no thank you. Decisions to include or exclude pre-sentential negative tokens were based on an analysis of discourse context and any relevant transcriber comments.

The nonanaphoric uses were then separated out, using discourse contextual clues to interpretation. Each nonanaphoric token was coded as (non)echoic up to deixis and as (in)consistent with a metalinguistic paraphrase. If a negative complement was not echoic at first glance at the context, I searched the remaining previous portion of the transcript and the transcript preceding that transcript for any evidence that the complement might be an echoic copy or a rote-learned construction. If none was found, the negative was coded as non-echoic. A negative was coded as consistent with a metalinguistic paraphrase if an exclamatory negative consisting of no way, don't say, etc. followed by the child's negative complement was felicitous in the discourse context. A metalinguistic negative was considered to be felicitous in context if an objection or rectification meaning was consistent with the logic of the discourse. In some cases there was absolutely no information available from context to determine which paraphrases were felicitous. These cases were treated as equally consistent with metalinguistic and descriptive paraphrases. If the context did not explicitly permit a metalinguistic reading, it was coded as inconsistent with metalinguistic paraphrase.

\section{RESULTS}

The purpose of the study was to test the hypothesis that children's nonanaphoric pre-sentential negatives are examples of metalinguistic exclamatory sentence negation. The specific prediction tested in this study is that these pre-sentential negatives are echoic up to deixis and compatible with metalinguistic paraphrases, like metalinguistic exclamatory sentence negation. A total of $45^{6}$ pre-sentential negatives (anaphoric and nonanaphoric) were collected from the transcripts of ${ }_{3} 3$ children. Thirty-one of these $(6.7 \%)$ were interpreted as nonanaphoric pre-sentential negatives. Twentytwo occurred with no, one occurred with never, and eight occurred with not. A total of five of these tokens were excluded for various reasons. Two no tokens and two not tokens were excluded because they occurred at the beginning of a new recording session and no previous discourse was available to test the echoic complement prediction. These were Darren's No Darren do it and Iris's No me got one, Lee's Not this thing comes, and Neil's Not Neil have it now (all from the Wells corpus). An additional no token included in previous studies, Nina's $(2 ; 1)$ No dog stay in the room given in (5), was excluded $(i)$ because it is impossible to tell whether the negative marker is a determiner or a sentence negation marker (both are equally viable analyses), and $(i i)$ because it may be a transcription error, suggested by the transcription of Nina's immediately following sentence. 
(5) Mother: What room does the dog stay in?

Nina: Here. No dog stay in the room. Don't talk stay in the room.

This left 20 analysable no/never tokens and six not tokens of pre-sentential negation from to children.

\section{No and never}

Of the 20 pre-sentential no/never negatives, i $6(80 \%)$ are echoic up to deixis and four $(20 \%)$ are not echoic up to deixis. All of the tokens are listed in context in (6)-(25).

Echoic complement

(6) Adam (2;3) Mother: Did you see the truck?

Adam: No I see truck.

(7) Adam (2;4) Mother: Well, is the sun shining?

Adam: No the sun shining.

(8) Adam (2;4) Ursula: Is the boy in the bed?

Adam: Boy bed. No a boy bed.

(9) Adam (2;4) Mother: 'Cowboy wear boots'?

Adam: No I wear boot(s) now.

(I0) Adam (2;10) Mother: Where are the other blast offs?

Adam: No dat blast off.

(I I) Eve (I;9) Mother: Fraser drink all tea.

Eve: $\quad$ No Fraser drink all tea.

(I2) Eve (I;IO) Eve: Mom sharpened it. No Mom sharpened it.

(13) Peter $(2 ; 2)$ Mother: D'you want me to cut it?

Peter: No Mommy cut it.

(14) Peter (2;2) Lois: Is Butch gonna go on the walk?

Peter: No no no, no Butch is gonna walk, too cold.

(15) Peter $(2 ; 3)$ Mother: That's a cake. We're gonna have it for dinner.

Peter: No that's a cake.

(16) Peter $(2 ; 6)$ Pat: Does it have a hole in it?

Peter: No it does have a hole in it.

(17) Nina (2;0) Mother: What's Mommy doing?

Nina: No Mommy doing.

(18) Nina (2;0) Mother: You don't want the lamb to have it either? Nina: No. No lamb have a chair either.

(19) Nina (2; I) Nina: I have nice lamps and Mommy touch it. Never Mommy touch it.

(20) Nina (2; I) Mother: Oh, I bet you let Leila have a turn too. Does Maggie push you? 
$\begin{array}{ll}\text { (21) Nath'l }(2 ; 7) & \text { Mother: Is Nathaniel a king? } \\ & \text { Nat: No Nathaniel a king. }\end{array}$

Non-echoic complement

(22) Eve (1;9) Mother: Why not? She's hungry...

Eve: No Mommy giving baby Sarah milk.

(23) Nina $(2 ; 0)$ Mother: You don't want me to have it?

Nina: No. No. No lamb have it. No lamb have it.

Mother: You don't want the lamb to have it either?

(24) Iris $(3 ; 2) \quad$ Iris: Open the [unintelligible speech]. Yes? No me got him.

(25) Nina (2; 1) Mother: What are you doing with it? (Nina throws puppet on the floor). Oh.

Nina: No my play my puppet. (Nina takes toys off her shelf. She starts throwing some of them) Play my toys.

These examples show clearly that the majority of children's pre-sentential no/never negatives are echoic up to deixis, as predicted. In a few cases, the echo and its target are different. But these differences all involve maintaining deictic reference, e.g. in (6), $I$ appropriately replaces you. In (8), an indefinite replaces a definite determiner. In this case, the child may simply have misheard the previous use of a determiner and replaced it. Further, in all of these cases the target of the negation is local to the negative utterance, and the negative complement does not include any additional information, as predicted. In two cases, (I4) and (I6), an inverted auxiliary in the target utterance occurs in prepredicate position in the echo. As I discussed above, both inverted and uninverted echoes are allowed following interrogatives. In only one case, (I 5), was a declarative statement with a reduced copula echoed. This copula was echoed as it appeared in the target. It is impossible to determine whether the children were echoing inversion in the other cases, because the $b e$ and $d o$ forms were not echoed.

\section{Metalinguistic exclamatory interpretation}

Of the 20 examples of pre-sentential no/never negatives, I 7 (85\%) are consistent with a metalinguistic exclamatory paraphrase and three ( $15 \%$ ) are not. The three tokens inconsistent with a metalinguistic paraphrase are, (22), (23), and (24). Example (22) seems most consistent with a prohibition reading in which the initial negative marker is suppletion with imperative don't, as De Villiers \& De Villiers had suggested. This reading would help explain why this negation is not echoic up to deixis, since prohibitions are 
not characteristically echoic up to deixis. The other cases remain as counterexamples to the prediction. For example, an exclamatory paraphrase like No way me got him or Don't say me got him is not a felicitous replacement for Iris's negative in (24), which was also paraphrased by the descriptive $I$ haven't got him by the transcriber.

The remaining 17 tokens were consistent with metalinguistic paraphrases. Two negatives are construed as presupposition cancellations. In (ro), Adam uses negation to cancel the presupposition that the object alluded to by his mother as a 'blast off' was actually such an object. This might be construed as a possible instance of Q-based negation, in Horn's terms, under the interpretation that Adam is objecting to the use of the term blast offs because he knows that another term is more appropriate, though he doesn't make it explicit verbally.

An R-based metalinguistic reading is compatible with ( 17 ), repeated below with discourse context as (26). Hereafter, I add the presumed intended readings of adult and child utterances to the examples in parentheses.

(Mother takes the whistle)

Mother: What's Mommy doing?

Nina: No Mommy doing (Don't say '(What's) Mommy doing'!). (Nina brings whistle to David. David and Linda laugh.)

Nina: David turn. David turn.

Again, an internal sentence negation paraphrase like Mommy is not doing (anything) is awkward, contra Deprez \& Pierce's (1993) suggested interpretation.

Examples (13), (20), and (21), repeated below with context as (27), (28), and (29) respectively, are consistent with an interpretation where the children are objecting to an indirect meaning presented in an indirect speech act (in parentheses). Clarifications like ' $[=y e s]$ ' were added by the transcriber.

(27) Mother: Do you want me to cut it? (Let me cut it)

Peter: No Mommy cut it (No way Mommy cut it!). (Peter cutting bologna ... with knife upside down)

(28) Mother: Do you let Nina have a turn on your bicycle?

Nina: No.

Mother: No you don't?

Nina: Uhhuh [= yes]. No

Mother: You just let Nina ride it?

Nina: Uhhuh [= yes].

Mother: Oh, I bet you let Leila have a turn too (Let Leila have a turn too). Does Maggie push you? 
Nina : Umhum [= yes]. No Leila have a turn (No way Leila have a turn!).

Mother: No?

Nina: No.

(29) Mother: It's not ice cream time.

Nat: What's this?

Mother: That's your glass. 'Bai' knocked your glass off. Ooh, king Nathaniel. (mockingly)

Nat: No king Nathaniel (Don't say 'king Nathaniel' to me!).

Mother: Is Nathaniel a king?

Nat: No Nathaniel a king (Don't say Nathaniel's a king!).

Mother: What is Nathaniel?

Nat: No king Nathaniel (Don't say 'king Nathaniel' to me!).

In (27), Peter's mother's utterance Do you want me to cut it? is easily interpreted as an indirect demand, e.g. Let me cut it!, which triggers an exclamatory response from Peter, who is determined to cut the bologna himself. An internal sentence negation paraphrase Mommy isn't cutting it is not a felicitous paraphrase here, since whether Mommy is or is not cutting the bologna is not the issue. Rather, Peter seems to be expressing an objection to letting his mother cut his food for him.

(28) is interpreted similarly. Nina's mother's utterance $I$ bet you let Leila have a turn too is rather clearly interpretable here as a polite form indirectly expressing a demand or request, e.g. Let Leila have a turn! This is a typical and acceptable use of indirectness in English discourse. Previous discourse reveals that Nina has already refused to let Leila have a turn on her bicycle and interprets her mother's utterance as an attempt to make her do something she has already expressed her unwillingness to do. One might paraphrase Nina's negative as meaning I object to Leila having a turn. Again, an internal sentence negation paraphrase like Leila doesn't have a turn is infelicitous, since the mother is not asking if Leila has a turn or not.

I would argue that all three of Nathaniel's negatives in (29) i.e. No king Nathaniel, No Nathaniel a king, and No king Nathaniel are exclamatory negatives. The meaning I want to assign to all three utterances is something like Don't say 'King Nathaniel' or Don't call me a king! I only discuss the middle instance here, since only this utterance observes the guidelines for pre-sentential negation discussed above. In (29), Nathaniel is annoyed at his mother for refusing to give him ice cream and knocks a glass off some surface (I use comments and transcriber notes to determine this scenario). In response to his mother's mocking reference to his strong will, Ooh king Nathaniel, Nathaniel uses No king Nathaniel to object to being called a king, e.g. I object to (being called) 'king Nathaniel', though the exact reason remains obscure. Nathaniel's second and third negatives seem connected to this first 
objection. The mother's Is Nathaniel a king? is not used to question the proposition 'Nathaniel is a king', which is obviously false, but to extend the indirect negative meaning introduced by her previous utterance. This leads Nathaniel to object again to the (royal) implication of the utterance with No Nathaniel a king (the objection reading of this utterance is supported by Catherine Snow (p.c.), who collected the data). In this particular case, an internal negation paraphrase like Nathaniel is NOT a king is acceptable. But the internal negation paraphrase leaves the fact that Nathaniel is using presentential negation to begin with a mystery.

Two other cases, (9) and the notorious (7), are consistent with a metalinguistic rectification meaning $I$ didn't mean $X$ or $I$ didn't say $X$. I illustrate my interpretation of $(7)$ using the expanded $(30)$.

(30) Adam $(2 ; 4)$

a Adam: Raining outside?

$b$ Mother: Raining outside. You go look out the window and tell me if it's raining.

$c$ Adam: No! Raining!

$d$ Mother: Is it raining?

$e$ Adam: Car... raining inside. Raining raining. Oh no raining (Oh no, it's raining).

$f$ Mother: Oh no, it's not raining.

$g$ Adam: No not raining (I didn't say '(It's) not raining').

$h$ Mother: Well, is the sun shining?

$i$ Adam: No the sun shining (I didn't say 'the sun (is) shining').

$j$ Mother: The sun's not shining.

$k$ Adam: Oh no the sun shining.

(30) is a discourse in which an adult speaker addresses a series of questions regarding the weather to Adam, who responds negatively in two cases. No not raining and No the sun shining. The key to understanding the logic of this discourse is understanding what Adam means by oh no raining in (3०e). This utterance has two reasonable interpretations. If $o h$ and no are treated as separate units, the utterance is interpreted as a negative, oh, no raining or $O h$, it's not raining. A second possibility is that oh no forms a constituent. In this case, Adam's utterance is read as affirmative, oh no, raining or Oh no! It's raining! - similar, in my opinion, to an adult's use of oh no to express surprise, Oh no! It's raining! Where's my umbrella?

One reason for choosing the second of the two interpretations is that Adam often uses oh no utterance-initially as a unit for expressing recognition of a negative event (real or imagined) as in the typical (31).

(3 I) Adam: Oh no hurt, tape recorder hurt. Screwdriver hurt.

Adult: You didn't hurt yourself with the screwdriver. 
Adam: Screwdriver screwdriver. Fix screwdriver. (Adam fixing tape recorder with screwdriver).

In (31), oh no hurt is infelicitous as a negative assertion like Oh it's not hurt. If this were the case, a logical incongruity would exist between the assertive force of the negative and Adam's subsequent attempt to fix the tape recorder, the referent for $i t$, with a screwdriver. I found no examples in Adam's transcript where oh no $X$ is used to express negation. I conclude that Adam's oh no hurt in (3 I) means $O h$ no, it's hurt and $O h$ no raining means $O h$ no, its raining in $(30 e)$.

The adult response ( $3 \circ f$ ) 'Oh no, it's not raining' is an attempt to clarify Adam's previous utterance. This is clearly indicated by the transcriber's use of double quotes, represented here as single quotes. Quotes are used in CHILDES transcripts to indicate clarification, as in the following example taken from the same transcript:

(32) a Adult: No, Adam shouldn't break Cromer's suitcase. He'd do without a suitcase.

$b$ Adam: Oh no... do suitcase.

c Adult: 'Do with a suitcase'? He'd have to do without a suitcase, because he wouldn't have one.

$d$ Adam: No no... have one. Oh no... have one. Have one

$e$ Adult: 'Oh no, he wouldn't have one'?

A felicitous interpretation of line $(32 b)$ is $O h$ no, do WITH a suitcase as the adult speaker guesses in $(32 c)$. The couplets $(32 b, c),(32 d, e)$ and $(30 e, f)$ are almost identical. I conclude that the adult's utterances $(32 c),(32 e)$, and $(3 \circ f)$ are clarificational.

I can now establish that the adult speaker has misinterpreted Adam's $O h$ no raining as a negation. This is because the clarificational $(3 \circ f)$ is in negative form, indicating that the speaker has assumed that Adam's statement was a negative, and she is simply looking for confirmation of her interpretation. A positive clarificational statement would seek to confirm the affirmative rather than the negative reading. This is an important point, because it links us to an understanding of Adam's two following negations in this discourse, $(3 \circ \mathrm{g})$ and $(3 \circ i)$, which contrasts with those found in the literature.

I now turn to ( $30 \mathrm{~g}$ ), Adam's No not raining. I shall assume not raining to be a subjectless pre-sentential negative for the purposes of the discussion (Deprez \& Pierce, I 993). Two possible descriptive interpretations for this utterance can be ruled out. No cannot be interpreted as anaphoric, followed by descriptive sentence negation, as in No, it's not raining. This would mean that Adam is simply acknowledging the adult's (3०f) 'Oh no, it's not raining'?, which I have already established to be a misinterpretation of Adam's Oh no raining. Further, the descriptive double negation interpretation $I t$ 's not not raining is infelicitous because negative assertions are infelicitous responses to 
clarifications, e.g. A: Did you say 'it's not raining'? B: *?It's not not raining. Moreover, double negatives like these are unattested in early child English. In contrast the metalinguistic rectification reading I didn't say 'It's not raining' is a felicitous reading of $(3 \circ \mathrm{g})$ in this context.

The next couplet, $(3 \circ h, 3 \circ i)$ is similar to $(3 \circ f, 3 \circ g)$. Out of context, $(3 \circ h)$ appears to be an ordinary yes/no question. However, the logic of the discourse thus far suggests that the question is clarificational. This leads us to interpret Adam's pre-sentential negation as something like I didn't say 'the sun (is) shining' either! The standard interpretation of this utterance is the descriptive the sun isn't shining (e.g. De Villiers \& De Villiers, 1985). However, if this was the correct interpretation, then the interpretation of the following couplet $(3 \circ j, 3 \circ k)$ would be a mystery. In $(3 \circ j)$, the adult speaker is again trying to clarify Adam's intended meaning, as shown by the transcriber's quotation marks. This would not be necessary, or felicitous, if Adam's previous presentential negation clearly communicated descriptive internal negation. Adam responds with $(3 \circ k), O h$ no the sun shining, which I interpret as $O h n o$, the sun IS shining! If this interpretation of $(3 \circ k)$ is correct, as our previous discussion of Adam's oh no utterances would suggest, and the De Villiers are correct and No the sun shining means the sun is not shining, then an (unnecessary) contradiction exists where Adam both asserts and denies that the sun is shining. If the pre-sentential negation means I didn't say 'the sun is shining', as I argue, then no contradiction is created and the discourse is consistent.

I conclude that Adam's two external negations no not raining and no the sun shining are best interpreted as metalinguistic rectification, e.g. I didn't say 'not raining'! and I didn't say 'the sun (is) shining'!, respectively.

Example (25), although not echoic, is used in a situation where Nina is obviously frustrated. In this situation the paraphrase No way my play my puppet!...My play my toy is felicitous. Example ( 18 ) allows the paraphrase No way lamb have a chair either!

Other examples like (I I), (I 2), (I4), (I 5), (I6), are functionally compatible with either a metalinguistic or descriptive (denial) paraphrase. The examples are listed in (33)-(37).

(33) Eve ( ; 9) Mother: Fraser drink all tea.

Eve: $\quad$ No Fraser drink all tea (No way Fraser drink all tea!).

(34) Eve ( $1 ; 10)$ Eve: I put hole in dit.

Colin: You did?

Eve: Mom sharpened it. No Mom sharpened it. (I didn't mean Mom sharpened it)

(35) Peter $(2 ; 2)$ Lois: Is Butch gonna go on the walk?

Peter No no no, no Butch is gonna walk, too cold.

(No way Butch is gonna walk!) 600 
(36) Peter $(2 ; 3)$ Mother: That's a cake. We're gonna have it for dinner.

Peter: No that's a cake (No way that's a cake!).

Mother: Yeah it's a cake. I just wanted to show it to you.

(37) Peter $(2 ; 6)$ Pat: With that nice umbrella you're still getting wet.

Peter: Yeah.

Pat: Does it have a hole in it?

Peter: No it does have a hole in it. (No way it does have a hole in it!)

Pat: Well then, I guess you're not getting wet then.

As the examples show, metalinguistic paraphrases are felicitous in context for these examples. This is sufficient to support the hypothesis.

\section{Pre-sentential not}

All 6 examples collected are presented in $(38)-(43)$.

(38) Eve ( 1 ;9) Colin: Will I read it or will you read it?

Eve: Eve read it.

Colin: Oh, Eve's going to read it.

Eve: Not Fraser read it.

Colin: Fraser's not going to read it?

Eve: Eve read it.

(39) Ben (I; I I) Mother: Going to have some candles are you?

Ben: Not you coming. Not you coming.

Mother: I'm coming to your party.

(40) Nina $(2 ; 2)$ Mother: Shall we build something else with your blocks or shall we put them away?

Nina: No. Not man up here on him head.

Mother: You putting the man on the dog, on the horse's head?

(41) Penny $(2 ; 3)$ Mother: I know I bought you a new one.

Penny: Put it down [with emphasis]. Not that clock upstairs.

(42) Katie (3;2) Father: You press the button.

Katie: No, not not I do it.

Father: You don't wanna press the button?

(43) Carl $(3 ; 0)$ Adult: He's naughty? Like you?

Carl: Not me naughty.

Adult: You're not naughty ... aren't you? 
Pre-sentential not negation is nether characteristically echoic up to deixis nor compatible with metalinguistic exclamatory paraphrases and therefore the examples do not support the predictions in this study. Only three examples $(50 \%),(38),(42)$, and (43), are echoic up to deixis and only two $(33 \%),(42)$ and (43), are compatible with metalinguistic exclamatory paraphrases, e.g. Katie's not I do it in (42) is consistent with the paraphrase Don't say I do it! I find (40) and (4I) uninterpretable.

However, each interpretable not token is formally ambiguous. In each case, it is not clear if the negation may apply either to the nominal to its right or to the whole sentence. As a result, they can be paraphrased either as contrastive sentence negation (defined above) or as contrastive constituent negation, e.g. Not Fohn but Bill. I illustrate using Eve's (38). One analysis of this example is that Fraser read it is an echo of Colin's previous I read it and Eve's entire negative is an example of contrastive sentence negation, e.g. Not 'Fraser read it'. I read it. Another equally viable analysis is that the negation applies only to the proper name Fraser, and should be read as contrastive constituent negation, not Fraser but Eve. Sentence-initial contrastive constituent negation of this kind is unacceptable in English. However, these utterances may reflect children's first attempts at contrastive constituent negation, which may express metalinguistic or descriptive negation (McCawley, 199I). The grammatical subjects in examples (39) and (43) occur with objective case which is compatible with the constituent negation option. However, I find both of these uses equally plausible.

To summarize, the pre-sentential no/never negatives support the hypothesis that children use pre-sentential negation as metalinguistic exclamatory sentence negation. The pre-sentential not negatives do not support the hypothesis. I discuss these results together with the results of Study 2 in the general discussion section below.

\section{STUDY 2}

\section{METHOD}

The subjects used in this study were the six children from Study I who used analysable pre-sentential no/never negation in their spontaneous speech (see Table I). The six subjects who only used (analysable and unanalysable) presentential not negatives as well as Darren, who used the unanalysable no negative, were not included in this study because the semantics of their negatives could not be confidently determined, as discussed above. The first 50 sentence negation tokens using don't and the first 50 sentence negations using not were collected from the transcripts of the six children (when available), beginning with their first transcript (see Table I). Each negation type was searched for separately because it is by no means clear that children use don't and not negatives in the same way. Informally, not commonly occurs with $d o$ or $b e$ in marked environments where negation is emphasized 
( $I$ am NOT a liberal!), while $n^{\prime} t$ is used in unstressed environments. Thus speakers (child and adult) might be expected to use not more often than don't to communicate objection and rectification in discourse. Combining negatives using both markers might have obscured any relationship between presentential no/never negation and negatives with these two markers. Second, there is a very small sample of pre-sentential no/never negation tokens. In treating don't and not negations as separate samples, smaller samples of data are available to statistically compare to the pre-sentential no/never cases. Only don't and not tokens where the marker negated the main or root clause of a sentence were included in order to match the pre-sentential cases. All of the tokens were coded for function (denial, nonexistence, etc.) using Bloom \& Lahey's (1978) criteria, and for metalinguistic objection and rectification functions. Then all of the tokens expressing rejection, denial, and metalinguistic negation were separated out. This was done to ensure a proper comparison set to the pre-sentential no/never negatives. Including nonexistence statements, for example, which are rarely used to express exclamatory negation and rarely echoic, would have severely biased the sample. Each token was then coded as having an echoic or a nonechoic complement, using the procedures discussed above.

\section{RESULTS}

The hypothesis was that children's pre-sentential negations are examples of metalinguistic exclamatory sentence negation. The prediction tested in this study was that if children's pre-sentential no/never negatives are either derivational or reductive variants of internal not/don't sentence negatives, then the internal negatives should be characteristically echoic up to deixis like pre-sentential no/never negatives.

A total of 194 main clause don't negatives and 220 not negatives were collected from the transcripts. Of these, $\mathrm{I} 30(66 \%)$ don't negatives and 172 $(78 \%)$ not negatives were codable as echoic or nonechoic rejections, denials, or metalinguistic negations (see Table 1 ). There were four logically possible types of internal negation to be found, not negation with/without echoic complement, and don't negation with/without echoic complement. Examples of all four types were found.

As a group, internal negatives with not and don't differ significantly from the pre-sentential no/never negatives with respect to the echoic up to deixis property. Study I showed that $16(80 \%)$ of children's pre-sentential no/never negatives were echoic up to deixis, while $4(20 \%)$ were not. Of the don't negatives, $38(29 \%)$ were echoic up to deixis and $92(71 \%)$ were not. Of the not negatives, $82(44 \%)$ were echoic up to deixis and ro5 $(56 \%)$ were not. The difference between expected and obtained frequencies across cell counts is significant $\left(\chi^{2}=21 \cdot 68(2), p<0.001\right)$. When the frequency of (non)echoic pre-sentential no/never negation is compared with the frequency of 
(non)echoic not and don't internal sentence negations separately using two $2 \times 2$ contingency tables, pre-sentential no/never negations differ significantly from the don't internal sentence negations $\left(\chi^{2}=19.38(1), p<0.001\right)$ as well as the not sentence negations $\left(\chi^{2}=8.3 \mathrm{I}(\mathrm{I}), p<0.005\right)$. I interpret this finding as support for the prediction that children's pre-sentential no/never and internal not/don't sentence negations are distinguished by the echoic up to deixis property.

I also found a significant difference in the frequency of echoic not and don't negations $\left(\chi^{2}=8.70(1), p<0.005\right)$. This is attributable to the fact that surprisingly many not negatives are copulas consistent with metalinguistic objection or rectification readings, e.g. Mother: You're too big? Well, then, you're too big to step on anybody. Adam $(2 ; 10): I$ NOT too big!, while the majority of don't negatives do not express metalinguistic negation, e.g. Mother: Are you tired, Adam?; Adam (2;6): No, I don't want to sit seat.

However, of the 27 internal don't rejections, e.g. don't want/don't like $X$, collected in the sample, $17\left(6_{3} \%\right)$ were echoic up to deixis. The difference between the number of echoic pre-sentential no/never negatives and the number of echoic don't negatives collected is not significant $\left(\chi^{2}=\mathrm{I} \cdot 59\right.$ ( $\left.\mathrm{I}\right)$, $p<0.25)$. This suggests that children's internal don't rejections and their pre-sentential no/not negatives do not differ with respect to echoic complementation.

\section{GENERAL DISCUSSION}

The hypothesis proposed in this paper is that children's pre-sentential negatives are expressions of metalinguistic exclamatory sentence negation. Two predictions of the hypothesis were tested. The first prediction, tested in Study $I$, is that pre-sentential negatives should be echoic up to deixis and compatible with metalinguistic exclamatory paraphrases in context, like metalinguistic exclamatory sentence negation. The second prediction, tested in Study 2, is that if children's internal sentence negation is not related derivationally to their pre-sentential negation, then they should not characteristically exhibit the echoic up to deixis property like the pre-sentential negatives.

The results of both Study I and Study 2 support the hypothesis with respect to pre-sentential no/never negatives. Study I shows that the vast majority of pre-sentential no/never negatives, like exclamatory negatives, are characteristically echoic up to deixis and compatible with metalinguistic exclamatory paraphrases, as predicted. Pre-sentential not negation is neither characteristically echoic up to deixis nor characteristically compatible with metalinguistic exclamatory paraphrases. However, pre-sentential not negation appears to be similar to either contrastive sentence negation, which is metalinguistic in nature though not necessarily exclamatory, or contrastive constituent negation, which may be used metalinguistically (rectification) or 
descriptively (McCawley, I99I). Thus, Horn's original suggestion that presentential negation expresses metalinguistic negation may still be true, although the pre-sentential not results do not support the stronger hypothesis pursued here that pre-sentential negation expresses metalinguistic exclamatory sentence negation.

Study 2 results suggest that children's internal not/don't sentence negation is not characteristically echoic up to deixis like pre-sentential no/never negation. This suggests that pre-sentential no/never and internal not/don't negation are formally distinct negation types, as we would expect if presentential no/never negation is exclamatory negation. However, no significant difference is found specifically between don't want/don't like rejection statements and pre-sentential no/never negatives with respect to rate of echoic complementation. Thus, these data are not counterevidence to Bloom's (I99I) more specific claim that children's pre-sentential negatives and their internal rejection statements are derivationally related.

These results suggest that three standard assumptions about child English pre-sentential negation should be reconsidered. First, children's presentential no/never negatives, in the majority of cases, appear to be legitimate, grammatical uses of metalinguistic exclamatory sentence negation. They do not seem to be primitive, non-adult-like, or otherwise ungrammatical variants of descriptive rejections or denials, as previously thought. This supports Bloom's (1970/1991) claim that pre-sentential negation does not reflect a 'stage' in the acquisition of internal sentence negation. Second, presentential not and internal not negatives do not characteristically exhibit properties of metalinguistic exclamatory negation like pre-sentential no/never negation. This suggests that pre-sentential no is not a suppletive alternant for pre-sentential not or internal sentence negation not, as commonly assumed, although not may be a metalinguistic contrastive negation marker in child English. 'Third, internal sentence negation using not/don't is not characteristically echoic up to deixis like pre-sentential no/never negation. This provides counterevidence to many analyses which either claim or assume that pre-sentential negation is derivationally related to internal sentence negation. Moreover, as mentioned above the rarity and restricted function of presentential negation are captured under the current hypothesis but go unaccounted for in previous analyses.

Though no counterevidence to Bloom's (1991) reduction analysis was found from Study 2, other considerations argue against this analysis. First, the analysis has been criticized as untenable for a number of reasons by a number of authors (e.g. Brown, 1973). These are well known and I do not review them here (see Drozd, I 993). Second, the meanings compatible with pre-sentential no/never negation are not generally compatible with don't want rejections. As I argue in Footnote I, metalinguistic opposition/rectification is not equivalent to the opposition meaning Bloom associates with don't want 
rejections: don't want simply does not mean don't say or no way. Since reduction is a syntactic mechanism, it is unclear how it could handle the change in meaning required to derive pre-sentential no/never negatives from don't want rejections. Third, aside from the apposition reading, it is unclear why children should select don't want rejections as the target for reduction to pre-sentential no/never negation, especially when other more compatible internal negations like metalinguistic uses of internal negation are available.

Two important issues remain. First, if pre-sentential no/never negation is exclamatory negation, then why do children use no instead of the negative phrases adults use to express exclamatory negation, like no way or don't say? Second, there remains the observation that pre-sentential negation disappears in child English (Bellugi, I967; Radford, 1990; Deprez \& Pierce, I 993), usually about the time that children learn to place not correctly before a predicate after a subject. This is a problem for my account. If children's presentential no/never negation is a legitimate use of exclamatory negation, why should they stop using it?

With respect to the first question, children may choose to use no as the productive pre-sentential marker rather than not simply because they have already learned the distributional properties of this marker (cf. Stromswold, I990) and know that pre-sentential not is generally only acceptable in contrastive uses, as the results from Study I seem to suggest. The fact that children use no as the suppletive exclamatory marker may be a reflection of a more general preference to use no as a general suppletive item in their early negatives. Bloom (1970) and De Villiers \& De Villiers (1979) observe that children often use no as a suppletive form for don't in prohibitions, e.g. no have that!, and sometimes confuse no with don't in successive utterances (Drozd, 1994).

The preference for no may also be the result of the fact that it is used in bare form to express objection and rectification in the input. De Villiers \& De Villiers (1979) show that the way Adam's and Eve's parents use negation is reflected in the speech of the children, though they argue for a different scenario from the one presented here. Though I agree with these authors that the use of pre-sentential negatives does not characterize a general stage in the acquisition of negation and that there are individual differences in the parents' uses of sentence negation, I do not agree that the children's presentential negatives mirror the adults' internal negation rejection (including prohibitions) and denial statements. First, the findings from Study 2 argue against the assumption that Adam's and Eve's pre-sentential negatives are early forms of internal sentence negations. Also, it is unclear how the De Villiers' findings would generalize to cases like Nathaniel's No king Nathaniel and No Nathaniel a king. Further, the De Villiers' assumption that early presentential negation is linked to their rejections and denials is not a necessary assumption. It is equally plausible that children exploit parents' uses of no to 
express objection as their model for using no in their pre-sentential negatives and later replace these negations with either metalinguistic uses of internal negation or don't say negatives. A preliminary search through the utterances of five children using pre-sentential no/never negation (Adam, Eve, Nina, Peter, Nathaniel) and their mothers for the string don't say reveals that both mothers and children use don't say to express objection to a previous utterance, e.g. Adam's $(4 ; 5)$ mother's I told you when I called you, don't say huh, Eve's (2;2) mother's Don't say that one again, Peter's (3; I) Don't say we don't got any of them, Adam's (2; 10) Don't say Captain Kangaroo write. Comparing these examples with those in (6)-(25) suggests that don't say generally may occur after the period in which the children use no in exclamatory constructions. However, don't say negatives do not appear to be characteristically echoic as expected. This may be because imitation decreases as language develops ( $\mathrm{I}$ thank an anonymous reviewer for making this clear to me).

Children also apparently use metalinguistic internal negation, as in the discourse, Lois: Is the Daddy a man? Peter $(2 ; 5)$ No, HE is not a man (Peter picking up peg 'boy'). Daddy's not a man. THIS is a man. The emphasized words in this example are marked as such in the text by the transcriber. I interpret Peter's negative not as denying that Daddy is a man but as a means of rectifying a possible misunderstanding in reference. The fact that Daddy is or is not a man is beside the point. What matters is that the peg 'boy' is a man.

I suggest that children's don't say and metalinguistic internal not sentence negations alternate with their later uses of pre-sentential no/never negatives and later replace them when they acquire the complete negation system. I leave a more thorough study of this point for further research.

With regard to the second question, it is important to note that the notion that pre-sentential negation eventually disappears in child English is only coherent when it is tied to the assumption that there is a derivational or reductive syntactic relation between pre-sentential and internal sentence negation. Under this assumption, pre-sentential negation is easily regarded as a developmentally intermediary construction which no longer serves a purpose once children learn to use internal negation.

The analysis proposed here supports an opposite claim - that children's pre-sentential no/never negation exhibits their use of exclamatory sentence negation, a grammatical negative construction in adult English. Under this approach, pre-sentential no/never negation does not disappear at all, since it is neither an ungrammatical derivational variant of internal negation nor an (ungrammatical) reduced multiclausal construction. The task for the child is not to learn to produce internal sentence negation but to learn the appropriate lexical forms for expressing exclamatory negation. By assumption, exclamatory sentence negation is used rarely in the input. Therefore, it follows 
that it will take some time for children to learn the idiomatic set of negative markers used in this construction.

\section{REFERENCES}

Bellugi, U. (r967). The acquisition of negation. Unpublished Ph.D. Dissertation, Harvard University.

Bloom, L. (1970). Language development : form and function in emerging grammars. Cambridge: The MIT Press.

- (199I). Language development from two to three. Cambridge: C.U.P.

Bloom, L. \& Lahey, M. (1978). Language development and language disorders. New York: Wiley.

Bloom, L., Miller, P. \& Hood, L. (1975). Variation and reduction as aspects of competence in language development. Minnesota Symposium on Child Psychology 9, 3-55.

Bowerman, M. (1976). Early semantic development : a cross-linguistic study with special reference to Finnish. Cambridge: C.U.P.

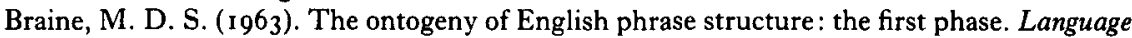
39, $1-15$.

Brown, R. (1968). The development of wh- questions in child speech. Fournal of Verbal Learning and Verbal Behavior 7, 279-90.

- (1973). A first language: the early stages. Cambridge: Harvard University Press.

Brown, R., Cazden, C. \& Bellugi, U. (I 969 ). The child's grammar from I to III. In Hill, J. P. (ed.), Minnesota Symposium of Child Psychology, Volume 2. Minneapolis: University of Minnesota Press.

Choi, S. (1988). The semantic development of negation: a cross-linguistic longitudinal study. Journal of Child Language 15, 51 7-31.

De Villiers, J. G. \& De Villiers, P. (1985). The acquisition of English. In D. I. Slobin, (ed.), The crosslinguistic study of language acquisition. Vol. I: The data. Hillsdale, NJ : Erlbaum.

De Villiers, P. \& De Villiers, J. G. (1979). Form and function in the development of sentence negation. Papers and Reports on Child Language Development 17, 57-64.

Deprez, V. \& Pierce, A. (1993). Negation and functional projections in early grammar. Linguistic Inquiry 24, 25-67.

Drozd, K. F. (1992). Child language negation as evidence for the metalinguistic/descriptive split. Paper presented at the 28th Regional Meeting of the Chicago Linguistics Society, University of Chicago, Chicago, IL.

- (1993). A Unification Categorial Grammar of child English negation. Ph.D. Dissertation, University of Arizona, Tucson.

- (1994). A discourse analysis of child English No. Paper presented at the Boston University Conference on Language Development, Boston, MA.

Fletcher, P. \& Garman, M. (1988). Normal language development and language impairment : syntax and beyond. Clinical Linguistics and Phonetics 2, 97-114.

Gleason, J. B., Perlmann, R. Y. \& Greif, E. B. (1984). What's the magic word? Learning language through routines. Discourse Processes 6, 493-502.

Greenfield, P. M. \& Smith, J. H. (1976). The structure of communication in early language development. New York: Academic Press.

Grice, H. P. (I975). Logic and conversation. In P. Cole \& J. Morgan (eds), Syntax and semantics 3: Speech acts. New York: Academic Press.

Horn, L. R. (1989). A natural history of negation. Chicago: University of Chicago Press.

Ito, K. ( $198 \mathrm{I}$ ). Two aspects of negation in child language. In P. S. Dale \& D. Ingram (eds), Child language : an international perspective. Baltimore: University Park Press.

Keller-Cohen, D., Chalmer, K. C. \& Remler, J. (1979). The development of discourse negation in the non-native child. In E. Ochs \& B. Schieffelin (eds). Developmental pragmatics. New York: Academic Press.

Klima, E. S. \& Bellugi, U. (I g66). Syntactic regularities in the speech of children. In J. Lyons \& R. J. Wales (eds), Psycholinguistic papers. Edinburgh: Edinburgh University Press. 
Lebeaux, D. S. (I988). Language acquisition and the form of the grammar. Unpublished Ph.D. Dissertation, University of Massachusetts, Amherst.

Liberman, M. \& Sag, I. (1974). Prosodic form and discourse function. CLS ro, 402-15.

MacWhinney, B. \& Snow, C. (1985). The Child Language Data Exchange System. Journal of Child Language 12, 271-96.

McCawley, J. D. (1991). Contrastive negation and metalinguistic negation. In L. Dobrin, L. Nichols \& R. M. Rodriguez (eds), CLS 17 : Papers from the 27th regional meeting of the Chicago Linguistics Society 1991. Chicago: Chicago Linguistics Society.

McNeill, D. (1970). The acquisition of language. New York: Harper \& Row.

Miller, W. \& Ervin, S. (1964). The development of grammar in child language. In U. Bellugi $\&$ R. Brown (eds), The acquisition of language. Monographs of the Society for Research in Child Language 29, 9-34.

Ochs, E. \& Schieffelin, B. (1979). Developmental pragmatics. New York: Academic Press.

Pea, R. (1980). The development of negation in early language. In D. R. Olson (ed.), Social foundations of language and thought: essays in honor of Yerome S. Bruner. New York: Norton.

Pierce, A. (1992). Language acquisition and syntactic theory: a comparative analysis of French and English child grammars. Dordrecht: Kluwer.

Radford, A. (1990). Syntactic theory and the acquisition of English syntax. Oxford: Blackwell.

Roeper, T. (1992). Acquisition architecture: from triggers to trees in the realization of IP and $\mathrm{CP}$. In J. Meisel (ed.), The acquisition of verb placement: functional categories and V2 phenomena in language acquisition. Dordrecht: Kluwer.

Shatz, M. \& McCloskey, L. (1984). Answering appropriately: a developmental perspective on conversational knowledge. In S. A. Kuczaj II (ed.), Discourse development: progress in cognitive developmental research. New York: Springer-Verlag.

Stromswold, K. J. (I 99o). Learnability and the acquisition of auxiliaries. Unpublished Ph.D. Dissertation, MIT.

Suppes, P. (1973). The semantics of children's language. American Psychologist 88, 103-14. Tottie, G. (1982). Where do negative sentences come from? Studia Linguistica 36, 88-105.

Volterra, V. \& Antinucci, F. (1979). Negation in child language. A pragmatic study. In E. Ochs \& B. Schieffelin (eds), Developmental pragmatics. New York: Academic Press.

Warren-Leubecker, \& Bohannon, J. (1984). Language in society: variation and adaptation. In J. B. Gleason (ed.) The development of language. Columbus, $\mathrm{OH}$ : Merrill.

Wells, C. G. (1981). Learning through interaction: the study of language development. Cambridge: C.U.P.

Wiche, R. T. P. (1991). External and verb phrase negation in actual dialogues. Fournal of Semantics 8, 107-25. 
APPENDIX

List of children by age and corpus

\begin{tabular}{|c|c|c|c|c|c|c|c|}
\hline & Subject & Age & Corpus & & Subject & Age & Corpus \\
\hline I & Abe & $2 ; 4-3 ; 4$ & Kuczaj & 63 & Lee & $1 ; 5-3 ; 3$ & Wells \\
\hline 2 & Abigail & $\begin{array}{l}2,4-3,4 \\
1 ; 5-3 ; 3\end{array}$ & Wells & 64 & Lee & $3 ; 0$ & Fletcher \\
\hline 3 & Adam & $2 ; 3-3 ; 4$ & Brown & 65 & Louise & $3 ; 2$ & Fletcher \\
\hline 4 & Adam & $3 ; 3$ & Van Houten & 66 & Lucy & $1 ; 6-2 ; 1$ & Howe \\
\hline 5 & Ada & $3 ; 3$ & Garvey & 67 & Martin & $1 ; 5-3 ; 3$ & Wells \\
\hline 6 & Alfred & $2 ; 6$ & Warren-Leubecker & 68 & Martin & $2 ; 5-2 ; 6$ & Gleason \\
\hline 7 & Allen & $2 ; 3$ & Warren-Leubecker & 69 & Matthew & $3 ; 1$ & Fletcher \\
\hline 8 & Anthony & $3 ; 3$ & Van Houten & 70 & Matthew & $3 ; 2$ & Fletcher \\
\hline 9 & April & $1 ; 10-2 ; 11$ & Higginson & 71 & $\operatorname{Max}$ & $3 ; 1$ & Garvey \\
\hline 10 & Ava & $3 ; 2$ & Garvey & 72 & May & $0 ; 11$ & Higginson \\
\hline i1 & Barry & $1 ; 6-2 ; 1$ & Howe & 73 & Megan & $1 ; 6$ & Warren-Leubecker \\
\hline 12 & Ben & $1 ; 5-3 ; 2$ & Wells & 74 & Melanie & $1 ; 6-2 ; 1$ & Howe \\
\hline 13 & Betty & $1 ; 6-3 ; 3$ & Wells & 75 & Michael & $3 ; 1$ & Fletcher \\
\hline 14 & Carl & $3 ; 0$ & Fletcher & 76 & Nan & $2 ; 10$ & Garvey \\
\hline 15 & Carol & $2 ; 6$ & Warren-Leubecker & 77 & Nancy & $1 ; 6-3 ; 3$ & Wells \\
\hline 16 & Charlie & $2 ; 11-3 ; 0$ & Gleason & 78 & Nanette & $2 ; 2$ & Gleason \\
\hline 17 & Craig & $3 ; 2$ & Fletcher & 79 & Naomi & $1 ; 2-3 ; 3$ & Sachs \\
\hline 18 & Daniel & $3 ; 3$ & Fletcher & 80 & Nat & $2 ; 8-3 ; 0$ & Bohannon \\
\hline 19 & Darren & $1 ; 6-3 ; 3$ & Wells & $8 I$ & Nathalie & $3 ; 2$ & Fletcher \\
\hline 20 & David & $3 ; 2$ & Fletcher & 82 & Nath'l & $2 ; 5-3 ; 4$ & Snow \\
\hline $2 \mathbf{I}$ & Debbie & $1 ; 6-3 ; 3$ & Wells & 83 & Neil & $1 ; 6-3 ; 3$ & Wells \\
\hline 22 & Doug & $2 ; 7$ & Warren-Leubecker & 84 & Neville & $1 ; 5-3 ; 4$ & Wells \\
\hline 23 & Effie & $3 ; 1$ & Fletcher & 85 & Nicola & $1 ; 6-2 ; 1$ & Howe \\
\hline 24 & Eileen & $1 ; 6-2 ; 1$ & Howe & 86 & Nicolette & $3 ; 3$ & Van Houten \\
\hline 25 & Ellen & $1 ; 5-3 ; 3$ & Wells & 87 & Nina & $1 ; 11-3 ; 3$ & Suppes \\
\hline 26 & Elspet & $1 ; 5-3 ; 2$ & Wells & 88 & Olivia & $3 ; 2-3 ; 3$ & Gleason \\
\hline 27 & Emily & $3 ; 2$ & Fletcher & 89 & Olivia & $1 ; 6-3 ; 3$ & Wells \\
\hline 28 & Eve & $1 ; 6-2 ; 3$ & Brown & 90 & Oliver & $3 ; 3$ & Fletcher \\
\hline 29 & Faye & $1 ; 6-2 ; 1$ & Howe & 91 & Oliver & $1 ; 6-2 ; 1$ & Howe \\
\hline 30 & Frances & $1 ; 6-3 ; 3$ & Wells & 92 & Patricia & $2 ; 5-2 ; 6$ & Gleason \\
\hline 31 & Garreth & $3 ; 3$ & Fletcher & 93 & Peg & $3 ; 1$ & Garvey \\
\hline 32 & Gary & $1 ; 6-3 ; 3$ & Wells & 94 & Penny & $1 ; 6-3 ; 3$ & Wells \\
\hline 33 & Gavin & $1 ; 6-3 ; 3$ & Wells & 95 & Peter & $1 ; 9-3 ; \mathbf{I}$ & Bloom \\
\hline 34 & Geoffrey & $1 ; 6-3 ; 3$ & Wells & 96 & Peter & $3 ; 2$ & Van Houten \\
\hline 35 & Gerald & $1 ; 6-2 ; 11$ & Wells & 97 & Phillip & $1 ; 6-2 ; 1$ & Howe \\
\hline 36 & Gina & $3 ; 1$ & Warren-Leubecker & 98 & Richard & $2 ; 8-2 ; 9$ & Gleason \\
\hline 37 & Graham & $1 ; 6-2 ; 1$ & Howe & 99 & Richard & $1 ; 6-2 ; 1$ & Howe \\
\hline 38 & Guy & $3 ; 0$ & Gleason & 100 & Robbie & $3 ; 0$ & Fletcher \\
\hline 39 & Harriet & $1 ; 6-3 ; 3$ & Wells & IOI & Ron & $3 ; 3$ & Garvey \\
\hline 40 & Ian & $\mathrm{I} ; 6-2 ; \mathrm{II}$ & Howe & 102 & Rosie & $1 ; 5-3 ; 3$ & Wells \\
\hline 41 & Ian & $2 ; 10$ & Garvey & 103 & Ross & $2 ; 6-3 ; 4$ & MacWhinney \\
\hline 42 & Iris & $1 ; 6-3 ; 2$ & Wells & 104 & Roy & $3 ; 2$ & Garvey \\
\hline 43 & Jack & $1 ; 5-3 ; 3$ & Wells & 105 & Sally & $1 ; 6-2 ; 1$ & Howe \\
\hline 44 & Jan & $2 ; 10$ & Garvey & 106 & Sam & $2 ; 11$ & Garvey \\
\hline 45 & Janna & $3 ; 2$ & Fletcher & 107 & Samantha & $1 ; 6-3 ; 2$ & Wells \\
\hline 46 & Jason & $1 ; 6-2 ; 1$ & Howe & 108 & Sarah & $2 ; 3-3 ; 4$ & Brown \\
\hline 47 & Jason & $1 ; 6-3 ; 3$ & Wells & 109 & Sarah & $3 ; 3$ & Van Houten \\
\hline 48 & Jeff & $1 ; 9$ & Warren-Leubecker & 110 & Scott & $1 ; 7$ & Warren-Leubecker \\
\hline 49 & Jennifer & $3 ; 0$ & Fletcher & III & Sean & $1 ; 6-3 ; 2$ & Wells \\
\hline $5^{\circ}$ & Jim & $3 ; 0$ & Garvey & 112 & Sheila & I $; 11-3 ; 3$ & Wells \\
\hline 51 & Jonathon & $1 ; 6-3 ; 2$ & Wells & 113 & Shem & $2 ; 2-3 ; 2$ & Clark \\
\hline 52 & June & $0 ; 11-1 ; 9$ & Higginson & 114 & Simon & $1 ; 5-3 ; 3$ & Wells \\
\hline 53 & Katie & $3 ; 1$ & Fletcher & II 5 & Stella & $1 ; 6-3 ; 3$ & Wells \\
\hline 54 & Katie & $3 ; 2$ & Garvey & 116 & Susan & $3 ; 2$ & Gleason \\
\hline 55 & Katie & $2 ; 4$ & Warren-Leubecker & I 17 & Tony & $1 ; 5-3 ; 3$ & Wells \\
\hline 56 & Kevin & $3 ; 3$ & Fletcher & 118 & Victor & $2 ; 3-2 ; 5$ & Gleason \\
\hline 57 & Kevin & $1 ; 6-2 ; 1$ & Howe & 119 & Wayne & $1 ; 6-2 ; 1$ & Howe \\
\hline 58 & $\mathrm{Kim}$ & $3 ; 0$ & Garvey & 120 & Wendy & $2 ; 0$ & Warren-Leubecker \\
\hline 59 & Kirstie & $3 ; 3$ & Fletcher & 121 & William & $2 ; 2-2 ; 3$ & Gleason \\
\hline 60 & Kirsty & $3 ; 0$ & Fletcher & 122 & Wisc & $1 ; 6$ & Miller/Chapman \\
\hline 61 & Laura & $1 ; 6-3 ; 3$ & Wells & 123 & Yvonne & $1 ; 6-2 ; 1$ & Howe \\
\hline 62 & Laurel & $2 ; 11-2 ; 0$ & Gleason & & & & \\
\hline
\end{tabular}

